\title{
The conundrum of coronary revascularization: Stent or bypass
}

\author{
Saswata Deb, MD, and Stephen E. Fremes, MD
}

See related article on pages 831-8.

Ischemic heart disease is one of the leading causes of death worldwide. ${ }^{1}$ Percutaneous coronary intervention (PCI) and coronary artery bypass grafting (CABG) surgery are the mainstream modalities for revascularizing patients with ischemic heart disease. In the United States, coronary revascularization is among the most common major medical procedures, with more than 1 million performed annually. ${ }^{2}$ In the past few decades, both of these modalities have undergone significant advances. Stents have evolved from being bare metal to drug eluting; further developments in the latter have resulted in advances in stent platforms, polymer coating, and antiproliferative agents. ${ }^{3,4} \mathrm{CABG}$ has gone through significant evolution with advances such as off-pump surgery and greater utilization of arterial grafting, including bilateral internal mammary artery and radial grafting. ${ }^{5-7}$ The question of which of these modalities is superior, fueled by such advances, has been the subject of numerous clinical trials, and the results have been aggregated in systematic reviews and meta-analyses. ${ }^{4,8-10}$

In this issue of the Journal, Smit and colleagues ${ }^{11}$ have performed a comprehensive meta-analysis involving 31 trials (of 15,004 patients, published between 1996 and 2013), comparing PCI with CABG, with a median followup of 5 years. The major findings are that $\mathrm{CABG}$ is protective against repeat revascularization compared with PCI, whereas stroke was more common in CABG. No differences were found in the proportion of myocardial infarctions; however, CABG had a slight advantage in mortality compared with PCI $(P=.05)$, especially in patients with multivessel disease (across all eras; Table 3 and Figure 2 in their article) and diabetes (in the drug-eluting stent era; Table 5 in their article). CABG and PCI were similar in comparisons of the on- and off-pump cohorts, although the number of studies reporting on stroke was limited (Table 4 and Figure 5 in their article).

\footnotetext{
From the Schulich Heart Centre, Sunnybrook Health Sciences Centre, University of Toronto, and Toronto Ontario Institute of Health Policy Management and Evaluation, University of Toronto, Toronto, Ontario, Canada.

Disclosures: Authors have nothing to disclose with regard to commercial support.

Received for publication Nov 9, 2014; accepted for publication Nov 10, 2014; available ahead of print Dec 11, 2014.

Address for reprints: Stephen E. Fremes, MD, Bernard S. Goldman Chair in Cardiovascular Surgery, University of Toronto, Schulich Heart Centre, Sunnybrook Health Sciences Centre, 2075 Bayview Ave, Room H405, Toronto, ON, Canada, M4N 3M5 (E-mail: stephen.fremes@sunnybrook.ca).

J Thorac Cardiovasc Surg 2015;149:839-40

$0022-5223 / \$ 36.00$

Copyright (C) 2015 by The American Association for Thoracic Surgery http://dx.doi.org/10.1016/j.jtcvs.2014.11.027
}

This study has some unique features. More specifically, the number of trials (and consequently, the number of patients) was large (Table 1 in Smit and colleagues ${ }^{11}$ ) and therefore strengthens precision; this current, up-to-date review is a good resource for the readership of the Journal. Another highlight is that, in addition to comparing the overall estimates of each endpoint, this study analysis is stratified by time, including the pre-stent era ( 9 trials, 5200 patients), the bare-metal stent era (14 trials, 4276 patients), and the drug-eluting stent era (8 trials, 5528 patients) for each primary endpoint. This stratification provided greater temporal detail with respect to study outcomes, which may have been affected by advances in both modalities. Lastly, sequential comparisons were performed from 0.5 years to 5-10 years of follow-up for the various primary study outcomes (Figures 8-11 in their article).

The study has several important limitations. Patient comorbidities, especially diabetes, and coronary anatomy are important factors to consider when deciding on the optimal treatment modality. Consequently, the authors performed multiple subgroup analyses with respect to patient and surgical factors, in addition to the longitudinal comparisons according to era. A more conservative alpha level, such as .01, may have been preferable, at least for the primary analysis, rather than the conventional .05 , to decrease the likelihood of making a type 1 error. If the investigators had adopted this analysis plan, aggregated results for revascularization (favoring $\mathrm{CABG}$ ) and stroke (favoring PCI) would still differ-very consistent with our general understanding; mortality, however, would no longer differ significantly in CABG versus PCI, which implies that all secondary analyses involving mortality should be interpreted with caution.

Another limitation is inherent within the endpoint of myocardial infarction. The definition of myocardial infarction after coronary revascularization has been evolving. ${ }^{12}$ Thus, the definition of myocardial infarction in the pre-stent era may differ from that in the drug-eluting stent era; this difference may have led to the heterogeneity of this endpoint. Another important consideration is that earlier trials randomized approximately $5 \%$ of the eligible patients, and they generally had low severity of coronary disease. ${ }^{13}$ The generalizability of results to current-day patients may therefore be hindered. Furthermore, large-registry data, such as that of the ASCERT (ACCF-STS [American College of Cardiology Foundation-Society of Thoracic Surgeons] Database Collaboration on the Comparative Effectiveness of 
Revascularization Strategies) study, ${ }^{14}$ are consistent with modern trials, which favor CABG with respect to mortality, even if the $P$ value of the meta-analysis is marginal. Finally, the median follow-up was 5 years, which may not be sufficient to elucidate differences for these endpoints.

Overall, Smit and colleagues ${ }^{11}$ should be congratulated for undertaking this large comprehensive meta-analysis on a topic that is multifactorial. This is a good compendium for the readership of the Journal. The main conclusions, based on results throughout history, are that PCI is associated with more repeat revascularization, whereas CABG is associated with a higher incidence of stroke. Furthermore, in the modern era of drug-eluting stents, mortality is lower in CABG patients with multivessel disease and diabetes, compared with PCI.

Despite the limitations mentioned, the findings of this study are provocative. Weaknesses persist in both modalities, including stroke for $\mathrm{CABG}$ and reintervention for PCI. The hope is that these weaknesses will drive clinicians, scientists, and industry innovators to continue pushing the envelope of research and technology to further address such issues.

\section{References}

1. Lim GB. Global burden of cardiovascular disease. Nat Rev Cardiol. 2013;10:59.

2. Epstein AJ, Polsky D, Yang F, Yang L, Groeneveld PW. Coronary revascularization trends in the United States, 2001-2008. JAMA. 2011;305:1769-76.
3. Stefanini GG, Holmes DR. Drug-eluting coronary-artery stents. N Engl J Med. 2013;368:254-65.

4. Deb S, Wijeysundera HC, Ko DT, Tsubota H, Hill S, Fremes SE. Coronary artery bypass graft surgery vs percutaneous interventions in coronary revascularization: a systematic review. JAMA. 2013;310:2086-95.

5. Cohn WE. Advances in surgical treatment of acute and chronic coronary artery disease. Tex Heart Inst J. 2010;37:328-30.

6. Martens TP, Argenziano M, Oz MC. New technology for surgical coronary revascularization. Circulation. 2006;114:606-14.

7. Taggart DP. Current status of arterial grafts for coronary artery bypass grafting. Ann Cardiothorac Surg. 2013;2:427-30.

8. Mohr FW, Morice MC, Kappetein AP, Feldman TE, Stahle E, Colombo A, et al. Coronary artery bypass graft surgery versus percutaneous coronary intervention in patients with three-vessel disease and left main coronary disease: 5-year follow-up of the randomised, clinical SYNTAX trial. Lancet. 2013;381:629-38.

9. Farkouh ME, Domanski M, Sleeper LA, Siami FS, Dangas G, Mack M, et al. Strategies for multivessel revascularization in patients with diabetes. $N$ Engl J Med. 2012;367:2375-84.

10. Fanari Z, Weiss SA, Zhang W, Sonnad SS, Weintraub WS. Meta-analysis of three randomized controlled trials comparing coronary artery bypass grafting with percutaneous coronary intervention using drug-eluting stenting in patients with diabetes. Interact Cardiovasc Thorac Surg. 2014;19: 1002-7.

11. Smit Y, Vlayen J, Koppenaal H, Eefting F, Kappetein AP, Mariani MA. Percutaneous coronary invervention versus coronary artery bypass grafting: a meta-analysis. J Thorac Cardiovasc Surg. 2015;149:831-8.

12. Lansky AJ, Stone GW. Periprocedural myocardial infarction: prevalence, prognosis, and prevention. Circ Cardiovasc Interv. 2010;3:602-10.

13. Taggart DP. Percutaneous or surgical revascularization in multivessel coronary artery disease: synthesis from SYNTAX. Eur Heart J. 2014;35: 2789-91.

14. Weintraub WS, Grau-Sepulveda MV, Weiss JM, O’Brien SM, Peterson ED, Kolm P, et al. Comparative effectiveness of revascularization strategies. N Engl J Med. 2012;366:1467-76. 